Fecha de recepción: abril 2020 Fecha de aceptación: mayo 2020 Versión final: junio 2020

\section{Disputa entre la materialidad arquitectónica y la imagen gráfica}

Rebeca I. Lozano Castro ${ }^{(1)}$ y

Alejandra Hernández Alvarado ${ }^{(2)}$

\begin{abstract}
Resumen: El siguiente artículo derivó de los hallazgos obtenidos del trabajo de campo realizado en la Tesis del Doctorado de Diseño de la Universidad de Palermo de una de las autoras, la doctora Rebeca Lozano Castro (2018). Con relación a eso, se presentan datos obtenidos sobre la percepción del arquitecto y el diseñador gráfico en su área de trabajo conjunto para las fachadas comerciales en la ciudad de Tampico, México. Fue reflexivo pensar en el trabajo llevado a cabo por profesionales de esas dos disciplinas en el planteamiento y la ejecución arquitectónica, pero también en el resultado visual de la comunicación entre la arquitectura y el diseño gráfico. Las edificaciones comerciales fueron consideradas desde su planeación de diseño, construcción, funcionalidad estructural, hasta la señalética interna. Sin embargo, eso no sucedió cuando se trató de la vinculación con el diseño gráfico identificativo-corporativo en la fachada comercial. Se identificaron casos de estudio particulares, con desvinculación en su producción visual-comunicacional como factor importante en el proceso de planeación-construcción arquitectónica comercial. Las conclusiones obtenidas representan un marco referencial para encauzar la planeaciónvinculación inclusiva entre la arquitectura y el diseño gráfico comercial expuesto en la vía pública, que pueda orientar la identificación y significación social de la cultura de Tampico. Palabras clave: Diseño Gráfico Corporativo, Arquitectura, Identificación.
\end{abstract}

Palabras clave: Diseño - Arquitectura - Identificación - Comunicación.

[Resúmenes en inglés y portugués en las páginas 112-113]

(1) Licenciado en Diseño Gráfico por Universidad del Noreste, Tamaulipas (1993). Se especializó con el Diplomado de Creatividad Gráfica Publicitaria del Centro Avanzado de Comunicaciones, A.C. México (1994). En 2004, obtuvo el Máster en Artes Gráficas, por Universidad Politécnica de Valencia, España. Doctora en Diseño por la Universidad de Palermo, Argentina (2018). Profesor de Tiempo Completo con Perfil PRODEP; Catedrática, Tutora, fue Coordinadora de Carrera Diseño Gráfico en Facultad de Arquitectura, Diseño y Urbanismo de la Universidad Autónoma de Tamaulipas, UAT. Fue miembro Comité Técnico para la generación del Examen General Egreso de la carrera de Diseño Gráfico a Nivel Nacional (CENEVAL EGEL-DISEG). Ha participado en Congresos Nacionales e Internacionales; ponente-expositor, publicaciones y artículos de investigación sobre educación en diseño, sustentabilidad y cultura en diseño. 
(2) Licenciado en Diseño Gráfico por la Universidad Autónoma de Tamaulipas (2003). Master en Diseño, por la Universidad Autónoma de Tamaulipas (2009). Doctoranda en el Doctorado en Comunicación en la misma universidad. Profesora de horario libre, presidente de Academia de Diseño Conceptual, Tutora. Ha participado en Congresos Nacionales e Internacionales; ponente-conferencista, publicaciones y artículos de investigación sobre diseño de información, infografía, comunicación visual y sustentabilidad.

\section{Introducción}

La ciudad de Tampico Tamaulipas, en México, mantuvo hegemonía sociocultural y comercial por parte de culturas extranjeras casi desde su fundación en el año 1828 hasta el día de hoy ${ }^{1}$ (Lozano, 2018, p. 65-69). Pero, con el T-MEC² (Tratado México, Estados Unidos y Canadá) esa hegemonía se vio representada con la competitividad comercial en la vía pública de la ciudad por medio de producciones gráficas. Las edificaciones contemporáneas e históricas que forman parte del paisaje urbano de esa ciudad, contienen identificadores gráficos en sus fachadas que funcionan como identificadores corporativos en el sector comercial. Esa representación, promueve la identificacion de los sujetos con imágenes que a su vez son empleadas por las empresas para identificar sus productos con fines de comercialización. De ese modo, las mercancías están vinculadas a un lugar ubicado en la vía pública y, en cierto modo, ofrecen el estatus de calidad que la sociedad demanda. De ahí que no sólo la fachada materializada cumple con una comunicación que se identifica con los gustos y necesidades sociales, sino que también el diseño corporativo forma parte esencial del discurso informativo hacia el espectador al estar expuesto exteriormente en la vía pública. Analógicamente, es posible compararse con la responsabilidad de la infografía (diseño de la información) en una parada de colectivos o la señalética interna en un edificio público.

En ese sentido, se considera al diseño arquitectónico como planeación encausada a la habitabilidad de espacios físicos (dentro de la arquitectura), y el diseño de las fachadas orientado a la atención de parámetros exteriores que expresan características de construcción y estilo, o corriente arquitectónica. De modo que se diferencian desde su planeación, funcionalidad, hasta sus materiales; por ejemplo, una edificación construida en esquina que presentará dos caras y recurre a una gráfica identificativa truncada que sea visible en ambas calles.

Es evidente que en el transitar, el diseño público transformó su imagen corporativa con características estéticas de formas, colores, tipografías, símbolos, composición visual y materiales de producción, con la finalidad de permanecer en la competencia comercial. Fue así como se generó tensión entre tradición y modernidad globalizada, desde el manejo del lenguaje visual hasta el mediático. Es decir, las gráficas identificativas ${ }^{3}$ comerciales con estilo gráfico-popular transformaron su discurso típico y coloquial; sus colores vivos y representativos de la cultura mexicana. Además de haberse presentado cambios en sus 
técnicas con acabado artesanal y su simbología con raíces de gráfica popular (entre otros aspectos), incorporaron tecnología e imitaron el estilo estadounidense. Probablemente, los diseñadores gráficos mantuvieron mayor preocupación por la producción gráfica y comunicación visual, que por la inclusión gráfica en la edificación comercial (no siendo esta arquitectura corporativa). En casos puntuales como franquicias, efectivamente existió una planeación inclusiva entre la producción gráfica y la estructura materializada arquitectónicamente. Sin embargo, no fue así para las edificaciones que existieron y los emprendimientos locales no franquiciados.

A finales de los años noventa, con la revolución tecnológica, hubo mayor impacto en las transformaciones de las fachadas y una desvinculación entre el discurso expuesto en la vía pública y su armonía compositiva. En esa observación, durante el trabajo de campo derivó el concepto de hegemonía sociovisual, donde se observó la emancipación gráfica popular (rotulación a mano alzada o artesanal) con relación al diseño corporativo moderno (con el uso de medios digitales e impresión con tecnología aplicada). Del mismo modo, ese concepto puede ser aplicado en la observación de la materialidad arquitectónica y el diseño gráfico en un mismo espacio, es decir, pensar cómo se manifiesta la hegemonía sociovisual en la materialidad del edificio, donde el diseño arquitectónico construido está por sobre el diseño gráfico. Las construcciones arquitectónicas mantienen producciones gráficas en sus fachadas, incorporadas, actualizadas en la edificación por primera ocasión y, sin embargo, carentes de una planeación clara inclusiva ${ }^{4}$ en sus proyectos. De modo que algunos de esos objetos culturales del diseño gráfico comunicacional cumplieron con su función visual identificativa más no comunicativa inclusiva en el edificio. Es decir, se cumplió con el objetivo de identificar un servicio comercial, empresarial, u otro, pero no se desarrolló una comunicación entre la estructura gráfica identificativa que efectivamente se incluyera en la construcción edificada (arquitectónica). Es decir, con la ausencia de planeación gráficacomunicacional en la construcción de la edificación comercial. Lo antedicho fue percibido por los espectadores, quienes, necesariamente además de ser atraídos por el impacto discursivo del rótulo comercial, también se integraron al consumo del servicio prestado y uso de los espacios materializados conforme a su identificación en un conjunto.

En el campo, se entrevistaron a profesionales de las disciplinas del diseño y la arquitectura obteniéndose opiniones dispersas que dieron mayor importancia a la arquitectura por sobre la gráfica comercial. Cuando se analizaron por separado las gráficas identificativas o el diseño corporativo en las fachadas comerciales, se entrevistaron a expertos de ambas disciplinas (arquitectos y diseñadores gráficos). Existieron coincidencias en relación a la desvinculación entre ambas planeaciones con base al fondo, pero también a la superficialidad material. Es decir, mientras los arquitectos dejaron para el último momento la colocación del diseño corporativo y consideraron la fachada de manera independiente, los diseñadores gráficos consideraron las dimensiones de la producción gráfica con respecto al lugar donde se colocaría (la distancia, el giro de la empresa, los materiales, la luz, entre otros aspectos). Pero no consideraron la estética del edificio, sus cualidades arquitectónicas, estilo, historia, entre otros, que definitivamente son parte de un conjunto estético, comunicacional y funcional para la identificación del usuario. 


\section{Enfoque Teórico-Metodológico}

Como aportes del diseño para este estudio consideramos al español comunicador Joan Costa en su libro Señalética Corporativa (2008), que ha encaminado sus esfuerzos a teorizar aspectos de comunicación en el diseño gráfico y ha indicado la importancia de la imagen de marca en la conformación de la identidad corporativa de una empresa. Asimismo, sus propuestas hacia la disciplina de la señalización corporativa, donde condiciona el vínculo entre la imagen de marca con la producción gráfica.

El método de Costa (1987) para la creación de sistemas señaléticos sugiere el conocimiento previo de normativas empresariales para el desarrollo de la identidad gráfica por parte del diseñador, que permita la relación simbólica entre la imagen, la arquitectura y el usuario (consumidor). Las empresas que poseen una normativa o clara identidad gráfica, indican considerar los elementos del diseño; por ejemplo, del código universal de colores, la selección de la gama de colores corporativos como parte de su propuesta de gráfica de identificación. Asimismo, la pertinencia de un apartado denominado condiciones arquitectónicas que indique cómo deben considerarse las características, el estilo, los materiales y estructura del edificio, antes de proponer una solución gráfica en este sentido. Lo anterior significó, para este estudio, la comprensión crítica-reflexiva sobre la adaptación de un medio de comunicación social que, a través de su imagen gráfica, se liga a una estructura arquitectónica (y viceversa). Así como la arquitectura está necesariamente enlazada a la composición grafica corporativa.

En ese libro de señalética, Costa describe premisas de orden señalético y destaca la necesidad de adaptación al medio; como premisa, el aspecto visual del gráfico no debe rebasar el plano de protagonismo del edifico, así como este último no debe rebasar la identidad grafica. Otra premisa descrita es la que refiere al gráfico identificativo posicionado y a la imagen grafica coordinada por sus colores y tipografía corporativa. Evidentemente, no lo sugiere como una aplicación promocional, sino como producto gráfico de la disciplina a la que pertenece, sumado a la comprensión y construcción mental de la identidad gráfica. Sin embargo, pensamos que la identificación lograda por medio de la gráfica identificativa, señalética u otro diseño gráfico, forma parte de las expresiones infográfícas (diseño de información). Eso es así, porque en el sentido etimológico los sistemas de señales son gráficos tridimensionales con información que hacen inteligible un espacio, ya sea público o privado, arquitectónico o natural. En ese sentido, el gráfico identificativo emplea propósitos no sólo instruccionales, sino que su concepción es parte de la expresión de identidad de la marca. Cada producción gráfica u objeto cultural de diseño, constituye un parámetro de identidad sociovisual de la empresa comercial. Por lo tanto, eso aporta a la percepción social sobre el diseño corporativo comercial en el imaginario cultural, porque se percibe como el cuidado y la planeación de la construcción edificada.

Lo aquí referido parte de un diseño flexible con hallazgos en el proceso investigativo a partir de una metodología de tipo cualitativa mediante la descripción y la interpretación de datos; por medio de una aproximación transdiciplinar desde la arquitectura, la antropología y la comunicación hasta el diseño como eje referencial. El método del historiador y filósofo estadounidense Thomas Kuhn (2004) es un referente para este estudio desde 
el aspecto descriptivo, en conjunción con la teoría de la arquitectura de José Villagrán (1980), con el funcionamiento de la edificación comercial y la comunicación con el entorno social. Esos paradigmas otorgan al análisis mayor profundidad con la relación a los factores socioculturales que inciden en el diseño y el conocimiento abstracto del estilo de vida de una sociedad.

Los datos aquí presentados parten del trabajo de una de las autoras, que se dividió en dos etapas; el primero, por medio de un modelo mecánico con estudios cualitativos con base a la observación etnográfica; el segundo, basado en los estudios de casos y datos construidos. Los estudios se realizaron en objetos gráficos corporativos, de lo micro a lo macro, con tiempos y espacios diferenciados. En el marco de ese enfoque, los datos se recogieron entre 2017 y 2018 de acuerdo a las construcciones arquitectónicas y gráficas presentadas. Lo referente a las unidades de análisis, se relacionó con el corpus de análisis constituido a partir de fuentes primarias de edificios comerciales de Tampico que tuvieron una repercusión en su construcción (inclusión o desvinculación) por la inserción del diseño corporativo. Las descripciones incorporaron pruebas relevantes sobre el diseño en la gráfica identificativa estudiado como fenómeno social para la construcción de evidencia empírica elaborada con respaldo teórico y procedimientos explícitos. Con respecto a las fuentes secundarias se recurrió a la bibliografía especializada y relacionada con el objeto de estudio, es decir, la inclusión gráfica corporativa en la edificación comercial.

Los sujetos entrevistados constituyeron una fuente de información importante sobre el discurso interdisciplinar entre la arquitectura y el diseño gráfico, que fue considerada y analizada. Esos sujetos se seleccionaron por su experiencia en relación a las disciplinas antes mencionadas. Pero también, por haber tenido relación con esa disputa de construcción mental y material. Las entrevistas semiestructuradas se desarrollaron centradas en el objeto de estudio y la experticia de los expertos guiaba la conversación con sus opiniones. El estudio generó un enlace constitutivo entre las disciplinas, que, si de alguna manera se observaron en sus particulares áreas de desarrollo, se unieron con la construcción que la sociedad hizo de ellas y su percepción unificada. También, se generó un registro fotográfico como evidencia de lo estudiado y eso permitió el análisis a profundidad de los aspectos semánticos de las fachadas, en su realidad social en el particular caso de Tampico. En este documento se agregaron solo las fotografías más significativas, de acuerdo con lo que se encontró y se relacionó con el punto medular del estudio.

\section{Miradas sobre la relación diseño y arquitectura}

La investigación de la que se desprende este artículo atendió a fenómenos tales como la hegemonía comercial y sociocultural, se derivó en la noción de hegemonía sociovisual para pensar al diseño gráfico. De modo que, cuando nos referimos al concepto sociovisual, esta relacionado con la sociedad-cultura y la visibilidad del diseño gráfico en diferentes contextos, tales como la vía pública. De acuerdo a eso, la hegemonía sociovisual se observó desde aspectos comunicacionales y sociales a partir de las gráficas identificativas o rótulos 
comerciales en fachadas comerciales de microempresas en la ciudad de Tampico. Sin embargo, esa lucha de fuerzas no sólo se presentó con la competitividad entre las microempresas, sino también en la materialidad arquitectónica. Es decir, en la misma edificación existió disputa entre lo construido en el edificio desde su planeación y diseño, hasta la colocación gráfica comercial del rótulo que lo identificó. Por ese motivo, particularmente, fue interesante observar cómo el diseño estuvo implicado en una disputa en su concepción planificada.

Fue así como el diseño gráfico corporativo comercialmente colocado para el público con una función de referente indicativo fue ocasionalmente impuesto, de manera improvisada, por parte de los profesionales de la disciplina. De tal modo que el papel del diseño corporativo por medio de la gráfica identificativa o rótulo comercial que identificó el conjunto arquitectónico, no fue considerado por ambas partes. Es decir, de manera independiente el arquitecto diseñó el edificio sin consideración de la parte gráfica, y el diseñador gráfico realizó su objeto identificador sin tener conocimiento de la arquitectura. Dicho de ese modo, la hegemonía sociovisual entre la arquitectura y el diseño gráfico se encontró presente en la materialidad de las edificaciones y conllevó a un efecto de sentido en el transeúnte o sujeto social en la vía pública.

Cuando se habla de estética también se habla de ideología, significación y cultura. En el caso particular de Tampico, la cultura se expresó por medio del diseño y su integración en las fachadas comerciales. Para comprender el proceso de materialidad entre el diseño corporativo y la arquitectura fue preciso considerar la diversidad en sus características culturales. El diseño corporativo moderno mantuvo hegemonía sociovisual con la emancipación de este por sobre la gráfica o rotulación popular tradicional en distintas épocas. Esa constante lucha por mantenerse al margen de la modernidad, generó productos culturales de diseño híbrido (Canclini, 2005).

Por un lado, el intelectual galés Raymond Williams (1980, p. 294) define a la hegemonía como un complejo entrelazamiento de fuerzas políticas, sociales y culturales diferentes que construyen y sostienen la conducción de una sociedad. Por otro, el sociólogo argentino Pablo Alabarces (2002) considera que toda cultura es híbrida, sin alusión del retorno con el pasado. Entonces la presencia hegemónica fue resultado de formas híbridas que al paso del tiempo derivaron de la emancipación gráfica-arquitectónica existente con la internacionalización de valores, ideología y prácticas; por parte de los sectores dominantes en la imagen visual representada del diseño gráfico en la arquitectura. Esos diseños populares-tradicionales o contemporáneos fueron producto de la narrativa de identificadores de origen, mitos y tradiciones. Es decir, llevaron huellas del lenguaje, de creencias representadas simbólicamente, del color característico de la cultura popular mexicana, entre otros aspectos socioculturales. Sin embargo, también fueron narrativa de historias vividas, entrelazadas y representadas identitariamente en su proceso de construcción. La arquitectura también fue producto de esas historias y la imagen gráfica representada en su materialidad formó parte importante del conjunto construido. Fue así que se consideró que ideológicamente y significativamente, con tensiones, innovaciones y cambios graduales, se proveyó la materialidad de la fachada arquitectónica. 
Respecto de eso, existen diversidad de opiniones que están de acuerdo o en desacuerdo con la inclusión o no de la imagen gráfica por medio del diseño corporativo. El Doctor en arquitectura Adán Espuna Mujica en una entrevista realizada 13 de febrero de 2017 menciona que desde la gestación del NAFTA (North America Free Trade Agreement) en el año 1992, comenzó a modificarse la fisonomía urbana de la ciudad con el corporativismo comercial. Es decir, como parte de ese proceso, apareció la Arquitectura Corporativa en Tampico como complemento de la marca e identificador de edificios comerciales. No solamente comercios extranjeros; también cadenas nacionales transculturizadas ${ }^{5}$ (mexicanas con imagen extranjera) como el caso de Soriana, tiendas de conveniencia Oxxo, o las farmacias Benavides, Del Ahorro y Guadalajara, entre otras. Asimismo, afirma que es mínima la referencia de la cultural local que se considera para el desarrollo de propuestas de diseño, y por tanto, predomina el desconocimiento sobre su procedencia histórica y transformación cultural de la zona.

De acuerdo al Dr. Espuna, el valor comunicativo y significativo de las edificaciones comerciales se concentró en la fachada de acuerdo con la época de la construcción y comunicó aspectos realcionadso a esa. Sin embargo, toda fachada mantiene comunicación con el entorno y es percibida por los usuarios. De modo que, pese a la simplificación hecha por la Arquitectura Corporativa, los sujetos sociales encontraron mayor percepción y significación en el valor comercial del edificio. Asimismo, Espuna compartió su opinión respecto sobre la importancia de la señal grafica como parte de la arquitectura, su vinculación y su finalidad orientada a las necesidades del usuario (dentro o fuera del espacio comercial). Pero, si su intención es comunicar comercialmente, no es parte fundamental de la arquitectura, es decir, la apoya pero no forma parte de la edificación. El doctor puntualizó cómo, si el diseño está basado en la forma o esquema empresarial comercial relacionado con la filosofía institucional, el aspecto comercial no posee privilegios en el proceso de diseño. Más bien, su funcionalidad pudiera ser de génesis o fundamentación teórica.

Por un lado, los responsables de la estética urbana resultante del empleo de los rótulos comerciales instalados en las fachadas de los comercios, van desde el encargado del diseño urbano y de la fachada del edificio, hasta el diseñador gráfico. Por otro lado, el papel del diseñador gráfico requiere que esté en concordancia con las normativas vigentes, la determinación de materiales y aspectos técnicos. De acuerdo a las teorías de Villagrán (1980), pensar en el valor estético desvinculado del aspecto social de la edificación comercial produce que el hábitat edificado esté incompleto. Es decir, no corresponde al espacio útil para el factible usuario o habitador y, en consecuencia, resulta carente de lógica u orden para éste. Como resultado, deriva el desconocimiento sobre el funcionamiento de la edificación comercial y la comunicación con el entorno social con la desvinculación en aspectos estéticos. Esa percepción conduce a la forma en que se le da importancia a la imagen gráfica en la materialidad de la construcción, provoca rupturas lineales de continuidad visual y de su significación. Esos nodos coexisten de forma acumulada en las fachadas comerciales que fueron construidas históricamente, pero también en las contemporáneas que no se planificaron incluyendo al objeto gráfico. 
Sin embargo, Kevin Lynch (2015) propone un escenario integrado, con una imagen nítida que desempeñe una función social con materialidad simbólica e histórica-comunicativasignificativa. Esa imagen integrada e inclusiva conduciría a la armonía visual construida y con el usuario aportando valores positivos, legibles, de confort en su experiencia y calidad en su estilo de vida. Es posible generar un objeto cultural ordenado que se identifique por su usabilidad, su estructura material y visual, desde el plano arquitectónico hasta la lectura gráfica. De acuerdo a Lynch, la imagen se distribuye analíticamente en tres partes: identidad, estructura y significado. La primera es con base a la identificación del objeto que contribuye a su distinción, individualidad o unicidad. La segunda está relacionada con su espacio, y su relación espacial con otros objetos. Precisamente, esos objetos pueden ser gráficos-legibles-visuales. La tercera se refiere a su significación emotiva. De modo que la relación espacial es factor integral para el desarrollo de una edificación inclusiva.

Con relación a eso, la perspectiva empírica del pensamiento de los arquitectos entrevistados persigue la formación de profesionales capaces de identificar las necesidades propias de la sociedad y vincularlas con los intereses comerciales de los empresarios. La educación parte de la premisa de que el estudiante debe estar formado en competencias para la solución de problemas con aportes transdiciplinares. En relación a eso, el arquitecto Jorge Torres entrevistado el 14 de noviembre 2018 coordinador de la carrera de arquitectura de la Facultad de Arquitectura, Diseño y Urbanismo, de la Universidad Autónoma de Tamaulipas, es responsable de la coordinación de la actividad denominada repentina estudiantil. Esa actividad representa un ejercicio académico que se lleva a cabo cada cursada de estudio en su universidad de origen y tiene varios propositos, entre ellos, propiciar el trabajo entre las tres diciplinas (Arquitectura, Diseño Gráfico y Diseño de Interiores) que alberga la institución educativa.

El arquitecto Torres comentó que el proceso de enseñanza-aprendizaje que desarrollaban los arquitectos docentes era laborar de forma independiente, y eso permeó en los estudiantes al hacerse evidente en los resultados de las repentinas. Es decir, en palabras de Torres, el estudiante de arquitectura diseña pero no toma en cuenta la propuesta gráfica en su proyecto arquitectónico. Esa es una de las razones por la que existen edificaciones que parecen estar contra las condiciones visuales de un logotipo. Definitivamente, lo compartido por los arquitectos entrevistados a partir de su experiencia con los estudiantes presenta dificultad en su conceptualización vinculada con la propuesta de diseño gráfico; como es el logotipo (o gráfica identificativa), y la noción del concepto gráfico.

Como se pueden advertir, existen complicaciones para conceptualizar y unir la marca comercial, gráfica identificatica (rótulo comercial) o propuesta gráfica, con la propuesta arquitectónica. A pesar de eso, los estudiantes de diseño gráfico presentan sus propuestas para solucionar casos de rediseño del espacio público y conceptualizan la idea con un desempeño aceptable en esos ejercicios académicos. De acuerdo a Torres, el aporte del diseñador gráfico radica en unificar los valores generales de la idea y contribuye de manera significativa en el ejercicio de la profesión del arquitecto. De tal forma, se diseñan piezas que en ocasiones no son requerimintos de algún proyecto, pero contribuyen efectivamente a las propuestas arquitectónicas. Es importante mantener la intención de trabajo colaborativo e integral por medio de repentinas a nivel de educación superior, que contribuyan al fortalecimiento del trabajo en equipo interdisciplinario con un objetivo 
en común. Ese trabajo académico encamina esfuerzos, que pueden derivar en un trabajo colaborativo para unir la ideación con el concepto, y viceversa. Es decir, desde la propuesta de imagen gráfica hasta la arquitectura comercial creando una configuración coherente entre la edificación y el diseño.

De acuerdo a Torres existen actores sociales que perciben las fachadas con vinculación e integración a la imagen de la empresa y su relación cultural. Eso es que, mientras en algunas ciudades es indistinta la concepción arquitectonica-visual, por el contrario, existen otras en las que lo prioritario es hacer esa observación, como el caso de Tampico, su identidad grafica y su hipersemantización ${ }^{6}$ (Chaves, 2003, p. 40-43). Con la imagen global de ciudad en constante transformación, su espacio accidentado presenta intervención profesional en comercios históricos y de nueva generación. En algunos de ellos, se observó una planeación estrategica a nivel de la comunicación visual; sin embargo, en algunos casos predominó la desintegración con la materialidad construida.

\section{Observaciones empíricas en las fachadas}

Precisamente, algo que se puede observar en las fraquicias exitosas en su comunicación identificativa es la coherencia entre todas las partes del diseño en la marca en las gráficas identificativas expuestas en las fachadas comerciales. Es decir, cuando observamos una franquicia, su fachada en el espacio comercial fue rediseñada para que la gráfica identificativa mantuviera una identificación apropiada por el espectador. Eso significa que las condiciones arquitectonicas contribuyen a través de su diseño a la conceptualización de la marca, y por tanto, el discurso se percibe como inclusivo, completo y complementario para los ideales del edificio comercial. La semántica que se presenta en el discurso visual se relaciona con una gráfica comercial coeherente en todos sus componentes, y por tanto, su circulación es recibida por los actores sociales como discursivamente sólida en su argumento, y su sintaxis es identificada, asignada e interpretada (Chaves, 2003). Cuando eso no sucede, el sujeto social se encuentra extrañado, confundido, y la percepción de esa gráfica identificativa es dudosa. Eso se interpreta por sujeto social y genera juegos semanticos creados a partir de la ideología presentada, como vínculo entre la sociedad y el producto o servicio. Por ejemplo, las llamadas edificaciones frankenstein (García y Kasis, 2009), donde no existe la integración global del diseño y, por tanto, no comunica correctamente en la edificación, o el concepto de cirugía estética en el diseño y la arquitectura con la idea de renovación y modernización, pero con resultados como la pérdida de identificación y reconocimiento.

Es distinto cuando una franquicia llevó a cabo los cambios en su fachada y se hizo visible en su producción por medio de formas, estructura, proporciones, color y textura. Al respecto García y Kasis (2009) afirman que el espectador la ubica de inmediato en su mente y la decodifica, asignándole una significación, apropiación y reconocimiento, generalmente acorde a la construcción consiente previa de la empresa. Es decir, reacciona de acuerdo a sus experiencias anteriores con la empresa u otra que haya sido relacionada con ella. Eso le permite su conocimiento, reconocimiento, memorización social, diferenciación, aso- 
ciación y valorización. El estilo de vida del sujeto social se ve comprometido con mayor confianza para su identificación y reconocimiento con la empresa. Entonces, la gráfica identificativa en la fachada constituyó el discurso silencioso del valor comercial de la empresa proveyendo un soporte comunicacional para la sociedad, aún cuando se trate de una empresa de nueva generación.

De acuerdo a Joan Costa (2007) las personas tienden a identificar a la empresa al mirar su edificación, posibilitando que la imagen y la identidad corporativa estén íntimamente ligadas a la cultura organizacional. Eso posibilita la circulación, recepción y reconocimiento, es decir, el intercambio discursivo (Dijk, 1996) entre el sujeto espectador y la imagen empresarial. Donde la perspectiva socio-económica de la empresa mantiene relación directa entre la imagen y la infraestructura o materialidad arquitectónica. Por ejemplo, es el caso de las franquicias (multinacionales) como Starbuks y Oxxo que, para la instalación de una nueva sucursal, derriban todo lo construido anteriormente. Esas edificaciones comerciales atienden de forma objetiva las condiciones que ligan al edificio con la marca, desde los materiales de construcción hasta la tipología de la edificación; atiende aspectos de diseño conceptual como color, graficos de apoyo, tramas y texturas (propuestas en la mayoría de los casos por el experto en comunicación visual).

Los casos anteriormente citados evidentemente tuvieron conocimiento, planeado y aplicado, con el diseño gráfico y arquitectónico inclusivo en sus edificaciones comerciales. El espectador tuvo la posibilidad de observar la gráfica identificativa cerca o lejos de la estructura arquitectónica y también su identificación simbólica, sígnica, como elemento identificador. Desafortunadamente, en ejemplos de empresas locales no sucede eso; más bien se infiere que por ser espacios comerciales alquilados, es pobre o nula la adaptación que se hace de su diseño corporativo. Precisamente, la hegemonía sociovisual parte del poco trabajo interdisciplinario e inclusivo entre las dos disciplinas, pero también por factores externos (como el recién mencionado).

Otro caso es la empresa local Zumba, que vende jugos y licuados de frutas, con la idea de productos saludables. Pero desde su gráfica identificativa hasta su estructura arquitectónica se observan con desorientación, es decir, sin la propuesta de un diseñador gráfico con ideales de imagen-marca. Ese caso es ejemplo de una empresa con un buen plan de negocios pero una mala imagen gráfica en su logotipo, su gráfica identificativa y su señalización, entre otros aspectos gráficos y paragráficos, externos e internos del lugar. Los únicos referentes para el espectador son los colores verde y amarillo particulares, que le permiten identificar dónde se encuentra; sin embargo, no existe una representación arquitectonica de la marca. La empresa Zumba hace uso exclusivo de lonas impresas que son colocadas en la parte superior de los locales comerciales alquilados. Las mercancías y el servicio que ofrece son buenos; sin embargo, la comunicación grafica de los conceptos podría representar verdaderamente un reconocimiento por medio de la consolidación entre la imagen gráfica y la arquitectónica.

Según Norberto Chaves (2003, p. 39-43) "La comunicación social y sus medios pasan de área táctica complementaria de la producción al campo estratégico de desarrollo". Se refiere a cómo los valores de la empresa deben ser percibidos e interpretados socialmente, por lo que la imagen gráfica permea de forma clara. Eso ocurre si el autor ejecuta una planeación clara de cómo el discurso influye en la conducta social, y el objeto de diseño 
se reinterpreta convirtiéndose en su significación. Por ejemplo, el envase y embalaje de los productos comerciales, cuya función era estrictamente utilitaria, ahora son medios que el diseño gráfico emplea para comunicar valores sociales. Posteriormente, se busca culturizarlos para después tomar significados asignados por la sociedad (como signos que le permiten identificarse), y forme parte de su estilo de vida. En palabras de ese autor, la ideología se vuelve mercancía y, por tanto, un bien capital.

Entre las funciones del diseño corporativo, está el discurso no verbal con la comunicación como mecanismo de interacción cultural entre lo presentado por la empresa y lo decodificado por el público. La imagen es una construcción consciente que refleja un "cuerpo institucional que se hipersemantiza" (Chaves, 2003, p. 39-43). Allí, todas las extensiones de la empresa son discursos de identidad, que van haciéndose cada vez más incluyentes en todos los posibles canales que el diseño corporativo puede emplear para ser detectado por el espectador. En la búsqueda por el reconocimiento, sus elementos comunicativos se exteriorizan como en el caso del envase, y su fachada emerge como rostro permanente expuesto en la vía pública comercial. De manera que la gráfica identificativa no se debe considerar menos importante que otros aspectos de conexión con el mercado objetivo. Eso es así, también, porque es un reflejo de la condición socioeconómica de la ciudad, de la sociedad y de la empresa que forma parte del paisaje urbano.

Otra realidad social de las fachadas comerciales es el vínculo ideológico que mantienen lingüísticamente al poseer el nombre de la empresa y la evocación mental que las personas hacen de la misma. Es decir, un sujeto social puede dirigirse a la empresa una vez que tiene una construcción mental de ella y, en su mente, existe una imagen de lo que espera encontrar de la empresa. En otras palabras, encontrarse con lo imaginado o lo idealizado confirma su seguridad y confianza en la empresa o, por el contrario, esto no ocurre si los símbolos no están creados en aras de una identidad icónica reconocible. Eso sucede cuando las fachadas distan de su composición arquitectónica inclusiva con la identidad corporativa que se ha diseñado para la empresa. De modo que se presenta un desfase en la comunicación, un error en la percepción del discurso, por lo que ya no alcanza el objetivo comunicacional hacia sus espectadores.

Pero si se consideran las exigencias de la sociedad hacia el diseño corporativo, es posible generar discursos inclusivos en aspectos visuales, materiales y visibles. Claramente, es una amalgama sólida de percepción inconsciente que se transforma culturalmente en medio de la construcción mental social (individual o colectiva) que reclama los signos como guías en la comprensión del espacio. De modo que es cuestionable el hecho que los arquitectos no conduzcan una planificación incluyente para el diseño y consideren la imagen visual, discursiva y lingüística, que los rótulos comerciales o gráficas identificativas aportan a las fachadas comerciales. Esa autonomía entre la arquitectura y el diseño gráfico debe repensarse y formar un vínculo inclusivo que conforme la identidad. En definitiva, simbólicamente existe una cercanía que, efectivamente, contiene una distinción en sus espacialidades simbólicas y necesarias.

Hablando de cultura e identidad, Alejandro Grimson (2011, p. 136) afirma que "[...] lo que antes se llamó distancia estructural o distancia simbólica, en realidad, fue la condensación de dos dimensiones que tienen plena autonomía (...) se trata de la diferencia entre la distancia cultural y la distancia identitaria [...]”. De ahí que la circulación con la expo- 
sición de esos objetos culturales de diseño (gráficas identificativas), al existir transformaciones se han modernizado, en ocasiones en conjunto con el diseño arquitectónico, pero no así complementados. Eso generó interpretativamente la confusión en la materialidad (arquitectura) y la identificación (imagen gráfica), que de acuerdo a ese autor, la confusión deriva empleando los términos de la sobreposición simbólica.

De modo que, si esa categorización mantuvo relación con el habitus (Bourdieu, 2012), está estrechamente ligada al contexto sociocultural e identitario. Precisamente, en Tampico las creencias mantienen vínculo con "el progreso" y la "modernidad", demostrando un efecto de sentido relacionado con la materialidad; y significativamente, con anhelos y deseos para la estabilidad del equilibrio económico representado interpretativamente con la arquitectura o producción construida. Aun cuando edificaciones históricas adoptaron las gráficas identificativas con soporte tecnológico implementado con la intención clara de mostrar actualización y contemporaneidad con la época, es probable que sean parte del imaginario social. No sólo del espectador o transeúnte, sino también del profesional del diseño y arquitecto.

Respecto de eso, es importante el conocimiento de la funcionalidad de la gráfica identificativa o rótulo en la fachada comercial por parte del profesional que lleva a cabo la planeación arquitectónica y construida. El diseño corporativo ubicado en la fachada, es el representante e identificador de esa estructura materializada y construida que alude a un servicio para el consumo. Por un lado, el edificio es la materialidad representada y diseñada de habitabilidad comercial, pero, por otro lado, la gráfica identificativa es la comunicación con el entorno social. Ambos casos cumplen con el grado de importancia que requiere ser considerado para beneficio del usuario.

El diseño corporativo forma parte de la arquitectura expuesta como estructura narrativa e imaginaria social que representa simbólicamente el tiempo vivido, la situación económica y política en ese contexto. De modo que, comercialmente, las rupturas y continuidades de la imagen urbana, se ven representadas en esos objetos culturales de diseño, visibilizados o invisibilizados; como parte de la identificación social y de la significación emotiva espacial. Todo eso genera un reconocimiento, tanto de legibilidad del espacio urbano, como de visibilidad y comunicación gráfica-comercial.

El arquitecto Robert Venturi (2011) se refiere a la presencia de los rótulos comerciales o gráficas identificativas como medios mixtos, de persuasión e información, a través de los cuales se usan palabras, imágenes y esculturas. Sin embargo, en ambos casos, la identificación se distingue en la mediatización en el espacio público por medio de formas, tamaños y estilos, complementados (o no) con carácter histórico o contemporáneo de la edificación representada (ver por ejemplo la imagen 1.1). 
Imagen 1.1. Gráfica identificativa (rótulo comercial) forzado a coincidir con la estructura arquitectónica.

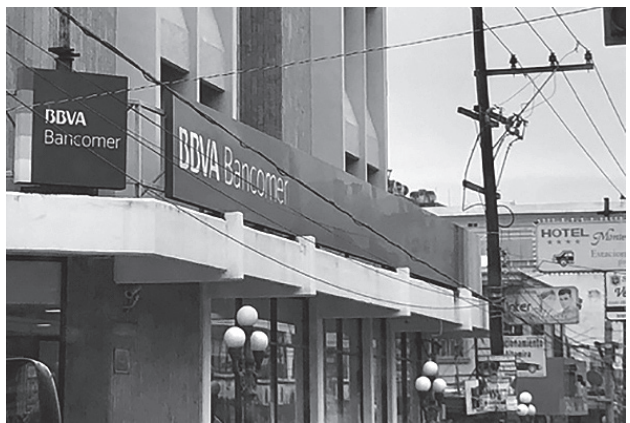

En la mayoría de los casos observados se encontraron gráficas identificativas (o rótulos comerciales) que fueron forzadas a implementarse como parte de las fachadas de edificios antiguos. Al realizar la adaptación del diseño corporativo en la superficie construida, no se preocuparon por que ambos elementos lucieran incorporados para evitar demeritar el uno al otro. Eso produjo un efecto como de falta de calidad, organización y responsabilidad por parte de la empresa que representó.

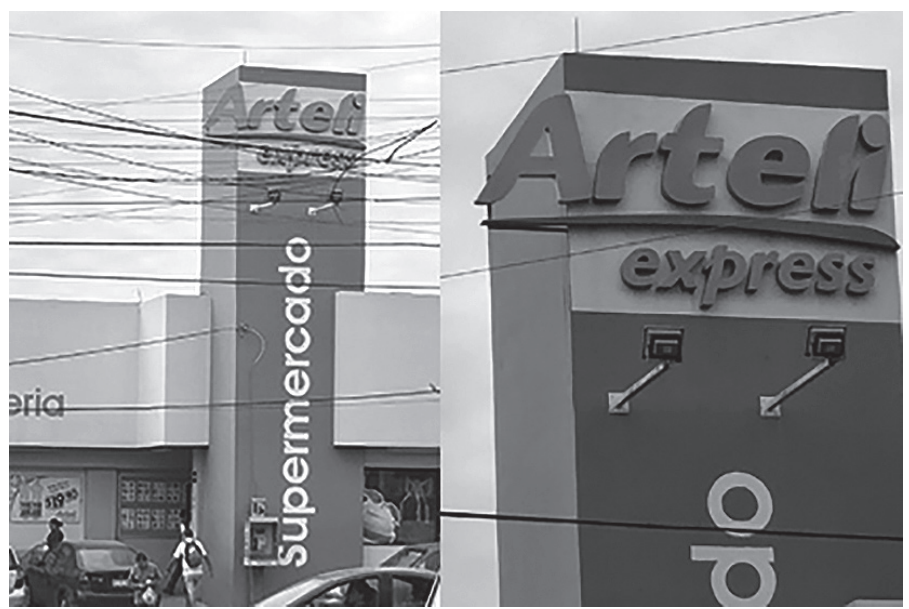

Imagen 1.2. Ejemplo de disputa entre la materialidad arquitectónica y la gráfica identificativa. 
El ejemplo presentado con la imagen 1.2 es totalmente claro en cómo se presenta el error gráfico al haber sido incorporado al diseño arquitectónico. Ese efecto generado, visualmente desproporcionado, que se percibe como error, también forzó al color. Precisamente por ese error, el color se tuvo que sujetar a un cambio en la parte superior con blanco de fondo para que se leyera, y las lámparas fueron mal colocadas. Definitivamente, no es funcional, a nuestro entender no es estético, ni produce una interacción discursiva con el reconocimiento esperado. En cambio, demerita la visibilidad de la gráfica identificativa; su significación y la arquitectura no se complementan en su materialidad con armonía y equilibrio.

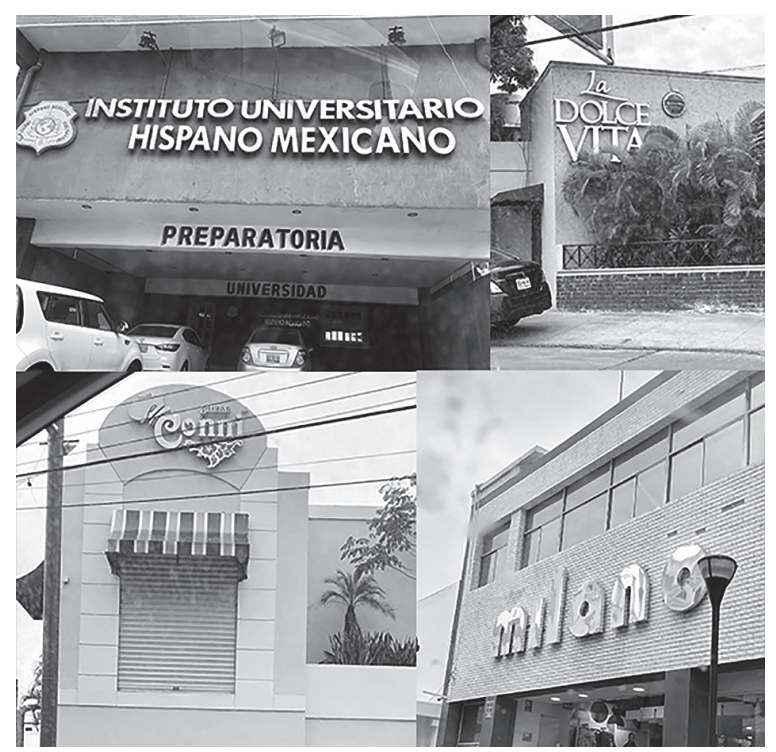

Imagen 1.3. Ejemplos de producciones gráficas identificativas con base a la impresión digital en lona.

En la imagen 1.3, se presentan ejemplos de gráficas identificativas donde el predominio fue la producción gráfica con impresión digital en lona en las fachadas. En efecto, no se tuvo consideración alguna, planeación ni inclusión con las estructuras comerciales. Será reflexivo considerar para otro estudio los factores que generaron esas condiciones en las producciones gráficas en detrimento de la percepción visual, donde predominaron los formatos cuadrados saturados de información y donde la percepción socioeconómica del negocio se relacionó con su exterior. 


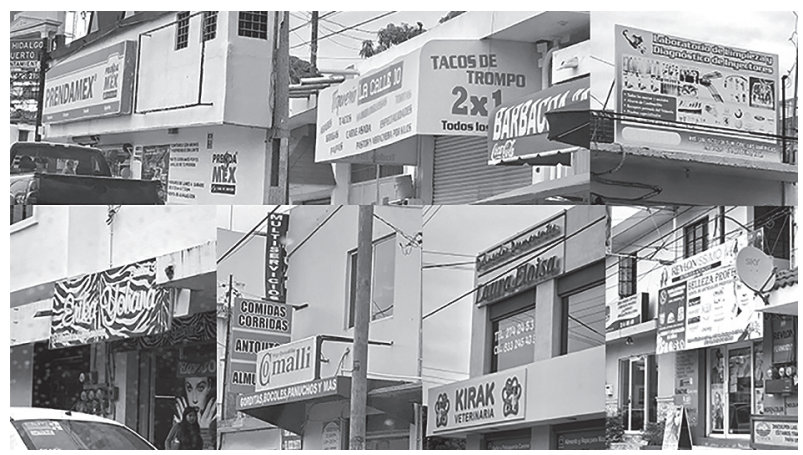

Imagen 1.4. Ejemplos de producciones gráficas identificativas donde el estilo de época se relacionó con la moda en los materiales, el aluminio no galvanizado, en tonos cobre, oro y plata.

En los últimos ejemplos presentados (imagen 1.4) se observaron producciones gráficas que demostraron haber buscado su "modernización" y de alguna forma su integración. Sin embargo, el empleo de letras de aluminio metalizado hizo que la imagen del comercio cambie, pero no se produjo distinción entre un giro y otro. Es decir, ese material fue utilizado tanto en gráficas identificativas de instituciones educativas, como en tiendas departamentales, restaurantes, zapaterías, ferreterías, bancos, entre otros. El aluminio no galvanizado representó una inversión considerable para los comercios, marcando cierta diferencia con relación a las gráficas identificativas con impresión digital en lona. Sin embargo, en uno u otro caso, el diseño corporativo no se integró en el diseño arquitectónico; no existió un profesional que hubiera ejecutado la planeación racional creativa para la toma de decisiones. El resultado fue la visibilidad fragmentada, excluida, que no se percibe como un mismo objeto cultural comercial (con un mismo concepto gráfico-arquitectónico) sino que, metafóricamente, es como el lienzo colocado sobre el caballete.

Todos los ejemplos anteriormente expuestos, se encontraron distribuidos en diversas partes de la mancha urbana. Fueron parte de la muestra general que se tomó para analizar si, en efecto, la disputa (hegemonía sociovisual) entre el diseño gráfico y la arquitectura en la materialidad comercial representa una realidad social. La posibilidad de complementarse el diseño gráfico con el diseño arquitectónico es necesaria y demuestra la importancia del trabajo interdisciplinario. Definitivamente, el diseño corporativo como objeto cultural fue resultado de estrategias retóricas adoptadas por grupos que ocuparon el espacio urbano y establecieron ahí sus símbolos. Esos grupos, de manera aislada, consideraron tópicos de los que partieron, pero que no advirtieron la vinculación, complemento y experiencia que producirían en la expectación del transeúnte; por ejemplo el caso del muralismo como experiencia en la vía pública, con códigos que produjeron y reprodujeron educativamente, y dieron forma a la gráfica de movimientos sociales. 


\section{Conclusiones}

La identificación es primordial para el posicionamiento de las empresas en el subconsiente de la sociedad, los aspectos arquitectónicos que se encaminan a reflejar la identidad gráfica de una empresa, coadyuvan en la interpretación coherente y sólida de la misma, donde la sociedad la percibe como un ente confiado, equilibrado, estable.

Las empresas que se preocupan por la identificación correcta de sus valores institucionales priorizan el ejercicio de una relación estrecha entre la imagen gráfica y la fachada del comercio. El carácter iconográfico de la ciudad se encuentra con mayor determinación para la búsqueda de una identidad como urbe, pero en ese sentido, puede ser identificado socialmente para que exista la construcción mental coherente al material. En efecto, se ejemplificaron muchos casos que discuten entre su propuesta arquitectónica y la identidad gráfica, pero cada vez son más las empresas interesadas por un trabajo inclusivo-completo en su presentación externa.

La academia (la universidad) como ente con carácter formador de profesionales al servicio y mejora de la sociedad, realiza acciones que apuntan a que se posibiliten, en poco tiempo, edificaciones arquitectónicas con identidad corporativa clara, inclusiva, que sea identificable para la sociedad. En efecto, aún no se han generado los profesionales que hagan ese trabajo integrado donde el resultado esperado sea con base al aporte en el sentido de pertenencia y el posicionamiento en la percepción (construcción mental) del espectador, de manera tal que evoque signos identificadores con claridad en el concepto comercial. Se pudo observar cómo la sociedad no posee plena conciencia de la disputa entre la materialidad arquitectónica y la imagen gráfica representada. Pero sí es percibida de manera inconsciente cuando las personas se expresan acerca de la confiabilidad o desconfianza que aporta una empresa. Los parámetros que generalmente mencionan son: "se ve mal terminado", o "el rótulo comercial es raro".

Definitivamente, el diseño corporativo debe abarcar la totalidad de los soportes y aplicaciones que promuevan la identificación y alcancen el reconocimiento de la empresa por parte de la sociedad. La realidad social es resultado de la expectación del transeúnte en la vía pública que identifica coherentemente o no, y percibe con su sentido común la construcción mental sobre la representación material de esa comunicación gráfica. Además, por medio del diseño corporativo en el diseño arquitectónico, se logra la evocación de conceptos de identidad que el gráfico identificativo comercial promueve. Al ser identificados socialmente, se posicionan en su conocimiento, en su percepción, en su imaginario, aportando mayor valor en la representación gráfica identificativa en las fachadas.

\section{Notas:}

1. Tesis doctoral titulada "Gráficas identificativas en fachadas de microempresas en Tampico", defendida el 1 de agosto 2018 por la Dra. Lozano Castro en la Universidad de Palermo, Buenos Aires, Argentina. Se puede consultar en https://www.palermo.edu/dyc/ doctorado_diseno/tesisdoctoral_lozano.html 
2. Firma del tratado entre México, Estados Unidos y Canadá (30 de noviembre 2018), con el que las tres naciones modernizan el TLCAN (Tratado de Libre Comercio de América del Norte) alcanzando un acuerdo comercial para las inversiones; PYMES, medio ambiente, anticorrupción y trabajo.

3. El Signo Visual Corporativo o la Gráfica Identificativa constituye un código visual autónomo en el seno de la Identidad Visual Corporativa; es un compendio complejo de connotaciones simbólicas que se legitima en cada una de sus reproducciones; su traducción simbólica es concentrada en un programa o manual de normas de uso que establece los procedimientos para su correcta aplicación.

4. Concepto referente a la inclusión gráfica o la integración entre la arquitectura y el diseño gráfico en las fachadas comerciales, pero no a los procesos de inclusión/exclusión social.

5. Desarrollo desigual con la desaparición gradual de la pasión nacionalista a la fuerza global.

6. Hipersemantización, como realidad en la mente de los sujetos sociales.

\section{Bibliografía}

Alabarces, P. (2002). Culturas de las clases populares, una vez más: la leyenda continúa. Nueve proposiciones en torno a lo popular. VI Jornadas Nacionales de Investigadores en Comunicación. Córdoba, Argentina.

Bourdieu, P. (2012). La distinción, criterio y bases sociales del gusto, (pp. 56-169; pp. 257 296). Buenos Aires: Editorial Taurus.

Costa, J. (1987). Señalética. Enciclopedia de Diseño (pp. 23-107, 122-137). Barcelona, España: CEAC.

Costa, J. (2007). Señalética Corporativa, (pp. 36-40). España: Autor editor.

Chaves, N. (2003). La imagen corporativa, (pp. 39-43). Barcelona, España: Editorial Gustavo Gili.

Dijk, V. (1996). Las estructuras y funciones del discurso, una introducción disciplinaria a la lingüística del texto y a los estudios del discurso. México: Editorial Siglo XXI.

Fernández, J. L. (1995). Estilo discursivo y planeamiento comunicacional. Oficios Terrestres, 1, 1-12. La Plata: Fac. de Periodismo y Comunicación Social, UNLP.

García Canclini, N. (2005). Culturas Híbridas, Estrategias para entrar y salir de la modernidad, (pp. 259-288). México: Editorial Grijalbo, S.A. de C.V.

García Santibañez, F. y Kasis, A. (2009). Problemas del Diseño Gráfico en la Arquitectura. Revista H+D Hábitat más Diseño, 2(1), 66-83. Recuperado de https://ninive.uaslp.mx/ xmlui/bitstream/handle/i/2740/revista_H+D_2.pdf?sequence $=2 \#$ page $=67$

Grimson, A. (2010). Culture and Identity: two different notions. Social Identities, 16 (1), 63-79.

Grimson, A. (2011). Los límites de la cultura, crítica de las teorías de la identidad. Argentina: Editorial Siglo XXI.

Lozano Castro, R. I. (2018). Gráficas Identificativas en fachadas de microempresas de Tampico, Transformaciones culturales y comunicacionales por impacto comercial, 1994 a 2013. Universidad de Palermo, Buenos Aires, Argentina. 
Lynch, K. (2015). La imagen de la ciudad, (p. 11). España: Gustavo Gili.

Venturi, R. (2011). Aprendiendo de las Vegas. Barcelona, (pp. 77-79). España: Editorial Gustavo Gili.

Villagrán García, J. (1980). Teoría de la Arquitectura, (pp. 29-53). Cuadernos de arquitectura y conservación del patrimonio artístico. Recuperado de https://es.scribd.com/ document/154039567/Teoria-de-La-Arquitectura-Villagran

Williams, R. (1980). Teoría cultural. Marxismo y Literatura, (pp. 294). Barcelona, España: Península.

\title{
Entrevistas
}

A. Espuna (comunicación personal a distancia, 13 de febrero, 2017).

J. Torres (comunicación personal, 14 de noviembre de 2018).

\begin{abstract}
The following article derived from the findings obtained from the field work carried out in the Thesis of the Doctorate of Design of the University of Palermo by one of the authors, Dr. Rebeca Lozano (2018). In relation to this, data obtained on the perception of the architect and graphic designer are presented in their joint work area for the commercial facades in the city of Tampico, Mexico. It was thoughtful to think of the work carried out by professionals of these two disciplines in the approach and architectural execution, but also in the visual result of communication between architecture and graphic design. Commercial buildings were considered from their design planning, construction, structural functionality, to internal signage. However, that did not happen when it came to linking with the identifying-corporate graphic design on the commercial facade. Particular case studies were identified, with disengagement in their visual-communicative production as an important factor in the process of commercial architectural planning-construction. The conclusions obtained represent a reference framework for guiding the inclusive planninglinkage between the architecture and commercial graphic design exposed on public roads, which can guide the identification and social significance of the culture of Tampico.
\end{abstract}

Keywords: Corporate Graphic Design - Architecture - Identification.

Resumo: $\mathrm{O}$ artigo a seguir derivou dos resultados obtidos a partir do trabalho de campo realizado na Tese do Doutorado em Design da Universidade de Palermo por um dos autores, Dr. Rebeca Lozano Castro (2018). Em relação a isso, os dados obtidos sobre a percepção do arquiteto e designer gráfico são apresentados em sua área de trabalho conjunto para as fachadas comerciais na cidade de Tampico, México. Foi atencioso pensar no trabalho realizado por profissionais dessas duas disciplinas na abordagem e execução 
arquitetônica, mas também no resultado visual da comunicação entre arquitetura e design gráfico. Os edifícios comerciais foram considerados desde o seu planeamento de projeto, construção, funcionalidade estrutural, para sinalização interna. No entanto, isso não aconteceu quando se tratava de ligação com o design gráfico de identificação corporativa na fachada comercial. Foram identificados estudos de caso específicos, com desengajamento em sua produção visual-comunicativa como um fator importante no processo de planejamento arquitetônico comercial-construção. As conclusões obtidas representam um quadro de referência para orientar a inclusão do planejamento-ligação entre a arquitetura e o design gráfico comercial expostos nas vias públicas, o que pode orientar a identificação e o significado social da cultura da Tampico.

Resumo: Design Gráfico Corporativo - Arquitetura - Identificação.

[Las traducciones de los abstracts fueron supervisadas por el autor de cada artículo] 